\title{
Estratégias de Leitura para e-book versus livro impresso: uma análise comparativa
}

Alessandra Bento Pereira Fernandes de Oliveira; Instituto de Letras, Universidade do Estado do Rio de Janeiro; E-mail: $<$ alessandra.bento.f@hotmail.com>.

Fátima Ribeiro de Castro; Instituto de Letras, Universidade do Estado do Rio de Janeiro, E-mail: <fatimarcastro@gmail.com>.

Grazielle Aleixo Reis; Instituto de Letras, Universidade do Estado do Rio de Janeiro, Rio de Janeiro, RJ; E-mail: <grazialeixo@hotmail.com>.

\section{Resumo}

O presente trabalho objetiva analisar as estratégias de leitura utilizadas em sala de aula com a aplicação do livro impresso e ebooks, à luz dos estudos de Koch, Marcuschi e demais críticos, buscando refletir sobre como as estratégias de leitura na formação e interação de sujeitos sociais viabilizam a existência de diferentes suportes de um texto.

Palavras-chave: estratégias, leitura, e-book.

\section{Introdução}

Os desafios socioeconômicos da sociedade brasileira, indiscutivelmente, permeiam o cotidiano escolar, portanto, fazse mister entender o potencial das novas mídias na construção de leitores críticos, ou seja, é importante que a informação continue chegando a todos para fonte de conhecimento e informação.

Nesse sentido, percebemos que as estratégias de leitura comumente adotadas na sala de aula de educação básica apoiam-se em dois eixos básicos: ativação do conhecimento prévio do aluno e discussão do texto, implicando essa discussão no levantamento de hipóteses/previsões e no estudo de pistas lexicais e contextuais que possam ensejar a compreensão do texto pelos alunos.

No entanto, é necessário ao professor ter bem claros os conceitos de leitura e seus processos e conhecer os fatores de 
natureza cognitiva, histórica, cultural e social que participam desse procedimento, se quiser formar leitores proficientes e críticos. Ao lançar luz sobre a problemática, é importante levar em conta algumas teorias, entre elas a Estética da Recepção, para o ensino da literatura. Tal corrente entende que a leitura é um processo único, individual e intransferível, em que o texto literário é considerado fator estético e social e que obra literária é concretizada no ato da leitura.

As diretrizes que norteiam os Parâmetros Curriculares de Língua Portuguesa já destacam que:

A leitura é o processo no qual o leitor realiza um trabalho ativo de compreensão e interpretação do texto, a partir de seus objetivos, de seu conhecimento sobre o assunto, sobre o autor, de tudo o que sabe sobre a linguagem etc. Não se trata de extrair informação, decodificando letra por letra, palavra por palavra. Trata-se de uma atividade que implica estratégias de seleção, antecipação, inferência e verificação, sem as quais não é possível proficiência. É o uso desses procedimentos que possibilita controlar o que vai sendo lido, permitindo tomar decisões diante de dificuldades de compreensão, avançar na busca de esclarecimentos, validar no texto suposições feitas (Parâmetros Curriculares Nacionais: terceiro e quarto ciclos de ensino fundamental de língua portuguesa/ Secretaria de Educação Fundamental: Brasília, 1998).

Nessa dimensão, a leitura se evidencia como um ato individual e coletivo, simultaneamente, e o processo de leitura como um todo complexo, de que participam elementos sociais, culturais, históricos e cognitivos, que interagem uns com os outros durante a leitura de um texto/obra. E se o texto proposto for literário, essa complexidade aumenta, uma vez que esse gênero textual solicita a presença de um leitor suficientemente preparado para "dialogar com ele" e trazer à tona os significados mais expressivos que subjazem nas suas "camadas" mais profundas. Portanto, a percepção do leitor, a sua capacidade de processamento do texto e o seu preparo para acionar estratégias metacognitivas durante a leitura devem ser estimuladas pelo professor, se a sua meta for a formação de um leitor não só proficiente, mas também crítico.

A leitura em sala de aula 
O processo de leitura que se desenvolve na sala de aula, quer no ensino fundamental, quer no de ensino médio, reserva pouco espaço para os alunos-leitores exercitarem suas capacidades, principalmente para dialogarem com o texto.

Com relação a esse diálogo entre leitor, texto e autor, na perspectiva de Wolfgang Iser (1996), o objeto literário não é o texto nem a experiência subjetiva do leitor, mas a interação entre ambos que se estabelece no processo de leitura. Nesse sentido, ele assim se expressa: "o texto ficcional deve ser visto principalmente como comunicação, enquanto a leitura se apresenta, em primeiro lugar, como uma relação dialógica." (Iser, 1996: 59).

Quanto a textos/obras mais densas, como ocorre no ensino médio, a situação de trabalho com leitura também é preocupante: são propostos aos alunos fragmentos de obras literárias mais consagradas da Literatura Brasileira, com o objetivo maior de se trabalharem características de escolas/movimentos literários e autores representativos de época, numa perspectiva cronológica, sem uma preocupação maior com o entendimento dessas pelos jovens leitores. As estratégias de leitura passam por rápida apresentação do texto aos alunos, leitura silenciosa, geralmente com o objetivo de detectar o vocabulário ainda desconhecido pelos aprendizes, perguntas (superficiais) dirigidas à classe (às vezes, de respostas óbvias), levantamento de algumas características específicas do autor, seguidas de outras da escola a que ele se filia, e conclusão do texto. Pouco ou nada se discute sobre o texto proposto. O saber prévio e o repertório individual de cada um não são acionados.

No que toca à questão das estratégias de leitura de e-books, entendemos que o leitor desenvolverá tais estratégias de acordo com os objetivos que ele tem sobre determinado texto. Há diferentes objetivos como, por exemplo, a leitura para obtenção de informações atuais, a leitura para aprendizagem e a leitura por deleite. Tais objetivos serão aclarados de acordo 
com os gêneros textuais escolhidos para a leitura. Além disso, são considerados também os conhecimentos prévios do leitor sobre o assunto e os tipos textuais.

Antes de estudarmos as diferentes estratégias, porém, nos deteremos ao estudo de Marcuschi (2002) sobre os gêneros textuais, mesmo que tangencialmente, a fim de delimitarmos tal conceito.

\section{Os gêneros textuais, segundo Marcuschi}

Os gêneros textuais são fenômenos históricos profundamente vinculados à vida cultural e social, ou seja, sendo eles, fruto de um trabalho coletivo, acabam por contribuir para a estabilização e ordenação das atividades do dia a dia, pois, além de entidades sócio discursivas, são formas de ação social incontáveis em qualquer situação comunicativa. Incontáveis, pois, de acordo com o estudo de alguns linguistas, chegou-se a nomear mais de 4000 gêneros, daí a desistência a uma classificação geral deles.

Quando o estudioso trata dos "novos gêneros e velhas bases", apresenta o conceito de suporte, explicando que são as novas tecnologias que proporcionaram o surgimento de diversos novos gêneros textuais, a partir de novos suportes - do rádio a internet, por exemplo. Sendo assim, ele deixa claro que esses novos suportes favorecem a criação de novos gêneros, mas que estes são todos ancorados em velhas bases, ou seja, gêneros já existentes.

As diferentes estratégias de leitura são: a leitura minuciosa e detalhada; auto monitoramento que é a verificação contínua de assimilação dos conteúdos; skimming que é a leitura de fragmentos seletivamente a fim de depreender as ideias principais do texto; scanning que é a leitura feita por uma passada de olhos para obter informações específicas sobre o tema central do texto. Quando o assunto não é de conhecimento do leitor, possivelmente ele fará uma leitura mais 
detalhada e, portanto mais auto monitorada, já que ele pretende compreender uma informação nova.

\section{O uso dos e-books em sala de aula}

O termo e-book é uma abreviação do termo electronic book e significa livro em formato digital. Pode ser uma versão eletrônica de um livro que já foi impresso ou lançado apenas em formato digital. Alguns dos formatos digitais mais populares são HTML, PDF, ePub, DjVu. Um e-book pode ser lido através do computador, iPad, Smartphone ou em dispositivo específico para este fim.

É importante que o professor tenha conhecimento dos recursos que podem ser utilizados para a leitura de um e-book, pois assim ele poderá integrar tecnologia e educação em sala de aula. De um modo geral, os e-books estimulam a leitura e facilitam $o$ acesso de docentes e discentes a determinadas obras. Contudo, deve-se considerar não só o conhecimento prévio do aluno sobre o assunto do texto, mas também sua habilidade com relação às novas tecnologias e sua acessibilidade. Para isso, é necessário que o professor conheça o perfil dos seus alunos a fim de adequar a melhor proposta de trabalho.

Os e-books podem ser lidos em diferentes meios como, por exemplo, tablets, celulares, leitores digitais portáteis e computadores. Eles possuem ferramentas que permitem ao leitor destacar partes importantes do texto, escrever comentários, consultar dicionários e, até mesmo, buscar uma informação específica com mais agilidade por meio de uma pesquisa com uma palavra-chave. Além disso, a intertextualidade no meio virtual é facilmente percebida com a existência de hiperlinks que tornam a leitura do indivíduo mais completa e aprofundada de modo que os conteúdos sejam inter-relacionados e se complementem. Nesse novo ambiente, o papel do professor não é de único meio de acesso à literatura, mas ele tem a função de dar subsídios aos seus 
alunos para que estes se tornem capazes de adquirir autonomia leitora e se aproximem do meio literário.

A retomada ao texto se dá por diferentes formas, já que a numeração das páginas de um e-book não coincide com as do livro tradicional. Portanto, cabe ao professor verificar diferentes possibilidades de referência, podendo se basear em capítulos ou porcentagem de texto lido, numerações alternativas de localização de determinado trecho.

Os leitores preferem marcar ou sublinhar fragmentos importantes do texto em um e-book uma vez que não há a preocupação de conservar o livro intacto. O leitor de e-books pode marcar ou desmarcar o texto quantas vezes julgar necessário, assim como é possível fazer anotações que são extremamente relevantes para a compreensão do texto. Os comentários feitos a partir de uma leitura denotam a interação entre autor, texto e leitor. Dentre as diversas ferramentas presentes no livro virtual, há a função de marcador de livro que facilita a continuidade da leitura do ponto em que parou.

\section{Resultado: análise comparativa}

Os dois gêneros possuem semelhanças e podem ser utilizados estrategicamente para estimular a leitura. A existência de um não implica na inexistência do outro.

A seguir, elencamos a forma como os dois gêneros podem ser utilizados em sala de aula:

- $\quad$ Estimular os alunos para a leitura de textos clássicos e contemporâneos e para o diálogo que se estabelece entre eles, mesmo que provenientes de épocas distintas e distantes.

- Reavaliar a produção literária de autores e por que razão merecem um enfoque em sala de aula.

- Trabalhar, junto aos alunos, a ideia de que a leitura de um texto literário é semelhante a um jogo em que "o autor dita as regras de funcionamento deste, por meio da tessitura, e o 
leitor descobre e redescobre como jogar, negociando sentidos, decifrando pistas sentidos, fazendo inferências, enfim, reconstruindo o jogo antes dirigido pelo autor." (Iser, 1999).

- Reavaliar os fundamentos que poderão dar um suporte teórico apropriado à sua realidade escolar. Levar em consideração, neste trabalho de reavaliação/reflexão, as abordagens mais frequentes nas aulas, selecionando os que mais se aproxima das necessidades dos alunos, em termos de formação literária.

Trabalhar, à medida do possível, com o texto literário na sua íntegra, não fragmentado e de forma contextualizada.

- Incentivar e desenvolver leituras comparativas entre textos produzidos por diferentes autores e em contextos e épocas diversificados. Reunir ou agrupar essas leituras por temas ou eixos temáticos facilitará o trabalho em sala de aula.

- $\quad$ Propor a realização de breves seminários ou textos escritos em poucas linhas sobre os textos trabalhados coletivamente, em aula, resumos, fóruns de debates e entrevistas, aproveitando ocasiões como os lançamentos de livros patrocinados por editoras e livrarias, feiras do livro, mostras culturais, filmes e outras.

- Desvincular o trabalho com literatura dos seguintes mitos: "Literatura é muito difícil", "Literatura é memorização sobre autor, obras e características literárias"; "Devem-se ler apenas os autores representativos de época, porque serão cobrados no ENEM/ Vestibular"; "Bastam os resumos dos livros", "É só ler uma resenha na internet”, entre outros mitos.

A fim de contextualizar o problema, foi elaborada uma pequena pesquisa* com alunos do Ensino Fundamental do Colégio Carolina Russo para conhecer o suporte em que preferem realizar suas leituras. Também foi aplicada a mesma pesquisa com os professores do colégio. 


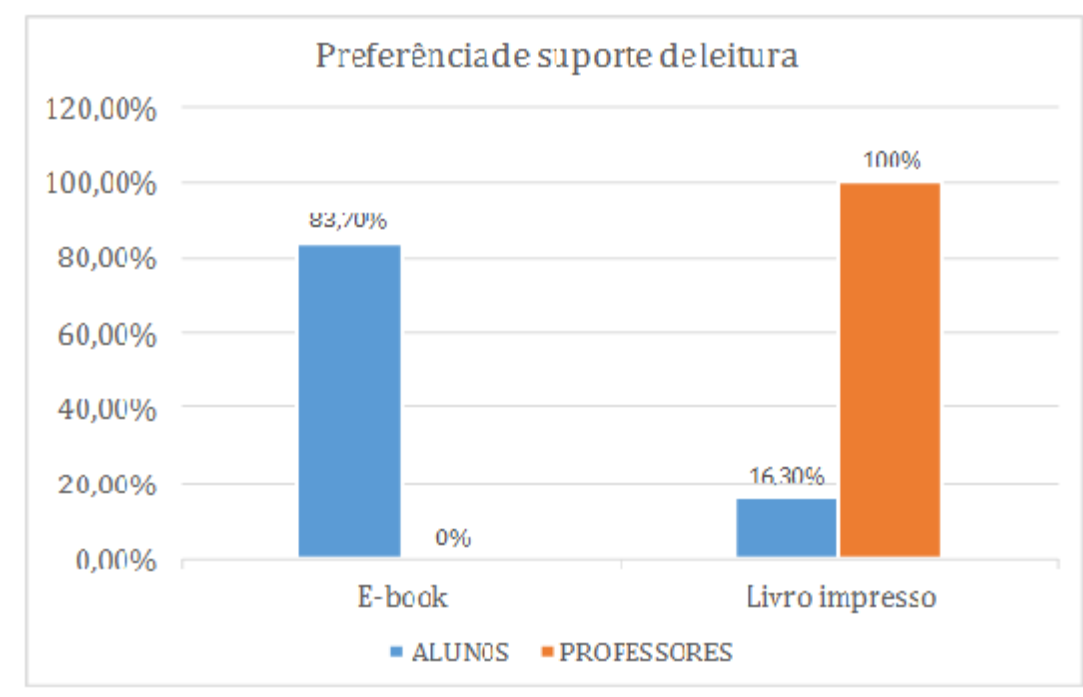

* Pesquisa realizada com alunos do Colégio Carolina Russo - Rio de Janeiro.

Total dos entrevistados: 43 alunos, do $4^{\circ}$ e $5^{\circ}$ ao do Ensino Fundamental. Faixa etária: $10-11$ anos. 15 professores do Ensino Fundamental. Faixa etária: 30-40 anos

\section{Considerações finais}

Sendo assim, quando se trata da relação livro/e-book/leitor/eleitor, toca-se na questão usuário/objeto, o que, nesse caso, consideramos como materialidade ou imaterialidade, que já foi tratada acima. Nesse sentido, o que encontramos é uma questão de adaptação e de aceitação de novos hábitos. Para a geração mais nova, a integração às novas tecnologias tem ocorrido sem traumas ou conflitos, já que já nascem, praticamente, alfabetizados digitalmente; diferentemente das gerações anteriores aos anos 90, cuja resistência ainda se mostra grande.

O que vale ressaltar desse estudo, portanto, é que, tanto os meios impressos, quanto os meios eletrônicos, produzem práticas de leitura e ambos devem estar a serviço da valorização dos alunos enquanto construtores do conhecimento de sua realidade.

\section{Referências}


Alliende, F. \& Condemarín, M. (2005). A leitura: teoria, avaliação e desenvolvimento. Porto Alegre: Artmed.

Elias, V. M. \& Koch, I. V. (2006). Ler e compreender: os sentidos do texto. São Paulo: Editora Contexto.

Iser, W. (1996). O fictício e o imaginário: Perspectivas de uma antropologia literária. Rio de Janeiro: Eduerj.

(1985) Os atos de fingir ou o que é fictício no texto ficcional.

In: Costa Lima, Luiz (org). Teoria da Literatura em suas fontes. V. II. Rio de Janeiro: Francisco Alves.

(1996-1999) O ato da leitura: uma teoria do efeito estético.

São Paulo: Ed. 34.

(1999). A interação entre texto e leitor. In: O ato da leitura.

Trad. J. Kretschemer. São Paulo: Ed. 34.

Jauss, H. R. (1994). A história da literatura como provocação à teoria literária. Trad. de Sérgio Tellaroli. São Paulo: Ática.

Koch, I. (1995). A coerência textual. 6. ed. São Paulo: Contexto. (1994). A coesão textual. 7. ed. São Paulo: Contexto. (1996). Argumentação e linguagem. São Paulo: Cortez. (2005). Desvendando os segredos do texto. 4. ed. São Paulo: Cortez.

- (1995) O texto: construção de sentidos. O texto em perspectiva, Porto Alegre, v. 9.

Lima, L. C. (1979). O leitor demanda (d)a Literatura. In: JAUSS, Hans Robert et al. A literatura e o leitor: textos de estética da recepção. Seleção, coordenação e tradução de Luiz Costa Lima. Rio de Janeiro: Paz e Terra.

Lotta, L. (2012). It's time to turn the digital page: Preservice teachers explore e-book reading. Journal of Adolescent \& Adult Literacy, 56. $280-290$.

Marcuschi, L. A. (2002) Gêneros textuais: definição e funcionalidade. In: Dionisio, A.P. e outros (org). Gêneros textuais e ensino. Rio de Janeiro: Lucerna.

- (2008). Produção textual, análise de gêneros e compreensão. São Paulo: Parábola editorial. 
Parâmetros Curriculares Nacionais. (1998). Terceiro e quarto ciclos de ensino fundamental de língua portuguesa. Secretaria de Educação Fundamental: Brasília.

Solé, I. (2003). Ler, leitura, compreensão: "sempre falamos a mesma coisa?" In: TEBEROSKY, Ana et al. Compreensão de leitura: a língua como procedimento. Porto Alegre: Artmed. 